\section{Influence of Nitrogen and Potassium Fertilization on Fruiting and Capsaicin Content in Habanero Pepper (Capsicum chinense Jacq.)}

\author{
Fátima Medina-Lara, Ileana Echevarría-Machado, \\ Ramón Pacheco-Arjona, Nancy Ruiz-Lau, \\ Adolfo Guzmán-Antonio, and Manuel Martinez-Estevez ${ }^{1}$ \\ Unidad de Bioquímica y Biología Molecular de Plantas. Centro de \\ Investigación Cientifica de Yucatán, Calle 43 \# 130, Col. Chuburná de \\ Hidalgo, Mérida, Yucatán, México 97200
}

Additional index words. pungency, Habanero pepper, plantlets, fertilization

\begin{abstract}
Habanero pepper (Capsicum chinense Jacq.) is a very important crop in Mexico and demand for it is increasing in national and international markets. The habanero pepper produced on the Yucatan Peninsula is considered of superior quality to that grown in the rest of the world as a result of its shelf life and pungency. Despite its importance, little research has been done on cultivation conditions that may affect its productivity and fruit quality. The effect of $N$ or $K$ fertilization on habanero pepper development and fruit pungency was evaluated. Plants under fertilization stress (control) had high capsaicin content. Nitrogen fertilization significantly increased plant growth and fruit while maintaining high capsaicin levels. Optimum response was produced with $15 \mathrm{~mm}$ urea as the $\mathrm{N}$ source. Potassium fertilization had no positive effects on growth or productivity. The $\mathrm{N}$ treatments modified endogenous $\mathrm{K}$ levels in the pepper plants and vice versa. The $K: N$ ratio (specifically in leaves and roots) varied between treatments with values greater than 1 in the $K$ treatments, near 0.5 in the control, and less than 0.5 in the $\mathbf{N}$ treatments. This parameter may be an important indicator of habanero pepper productivity and requires study under different fertilization regimes.
\end{abstract}

The present manifestation of any plant is the product of years of evolution from simpler organisms, in the form of biotic and abiotic changes, in response to environmental transformations. Capsicum peppers are under heavy demand in international and national markets, are eaten fresh or dried, or processed into a variety of end products. Hot peppers are popular food additives, valued for their color, pungency, and aroma (Bosland, 1992). In Mexico, hot peppers constitute both part of national traditions and cultural identity.

In recent years, the habanero pepper (Capsicum chinense Jacq.) has become increasingly important as a result of its wide diversity and its high fruit pungency, which make it very desirable in many countries. Pungency in habanero pepper fruit depends on environmental factors, including soil type, osmotic properties, and nutrient components; the latter is the least studied (Soria-Fregoso et al., 2002). Phenotypic expression of pungency is therefore produced by a genotype $x$ environment interaction (Harvell and Bosland,

Received for publication 8 Feb. 2008. Accepted for publication 10 Mar. 2008

This research was supported by a grant from the Fundación Produce Yucatán (Project 0510).

We thank Eliazar Xool for providing the Habanero pepper plants.

${ }^{1}$ To whom reprint requests should be addressed; e-mail luismanh@cicy.mx
1997). Pungency results from the presence of capsaicinoids, which are vanillylamine acid amides and $\mathrm{C}_{9}$ to $\mathrm{C}_{11}$ branched chain fatty acids; capsaicin and dihydrocapsaicin account for $\approx 80 \%$ of all capsaicinoids in peppers (Bernal et al., 1993). During fruit ripening in habanero pepper, capsaicin concentration progressively increases, reaching a maximum 45 to $50 \mathrm{~d}$ after fruit set (Contreras Padilla and Yahia, 1998). Capsaicin then reverts and degrades to other secondary products.

The same agricultural practices are often used for sweet and hot pepper species, although these crops differ in growth, habit, and fruiting characteristics. Little is currently known about the effect of soil nutrients on pepper fruit pungency and very few measurements have been taken in commercial pepper fields. Reports have documented $\mathrm{N}$ and $\mathrm{K}$ effects on sweet pepper (Jaworski et al., 1978) and hot pepper (Johnson and Decoteau, 1996). No published data exist, however, for $C$. chinense Jacq, although for maximum yields, the recommended $\mathrm{N}$ level, in cultivated soils, is $125 \mathrm{~kg} \cdot \mathrm{ha}^{-1}$ and that for $\mathrm{K}$ is $150 \mathrm{~kg} \cdot \mathrm{ha}^{-1}$ (Soria-Fregoso et al., 2002), but today, it is very important to emphasize that there are no data in habanero pepper that indicate an adequately fertilized protocol.

Fruit yield and quality depend on fertilization among other agricultural inputs (Epstein and Bloom, 2005; Raese and Drake, 1997). Even at low levels, fertilization often enhances yields dramatically, although excessive fertilizer application can negatively affect crop nutrient efficiency and produce diminishing financial returns (Epstein and Bloom, 2005). The fertilization regime also affects the concentrations of many secondary metabolites such as alkaloids (e.g., capsaicin), phenols, and others (Bryant et al., 1987; Gerson and Kelsey 1999; Gremigni et al., 2003; Kainulainen et al., 1995).

Habanero pepper is an extremely important crop in Yucatan State, Mexico, but no data have been gathered on its responses to $\mathrm{N}$ and $\mathrm{K}$ fertilization, particularly how it may influence fruit development and quality. In response, the present study aim was to analyze if addition of $\mathrm{N}$ or $\mathrm{K}$ increases fruit capsaicin levels or affects fruiting in habanero pepper under greenhouse conditions.

\section{Materials and Methods}

\section{Materials}

Analytical-grade reagents and solvents were used without further purification. The capsaicin standard was purchased from Sigma Chemical Co. (St. Louis) and dissolved in absolute ethanol. Precoated, aluminium-backed silica-gel ${ }_{60}$ chromatographic sheets $(20 \times 20 \mathrm{~cm})$ with fluorescence indicator $\left(\mathrm{F}_{254}\right)$ were used in the analyses (item 105554; Merck, Darmstadt, Germany).

\section{Plant material}

Three-week-old habanero pepper plants of an orange-fruit local variety (Habanero Naranja), germinated from seeds in peatmoss (Cosmo Peat, Cosmo cell distributor), were obtained at Chicxulub, Yucatan, Mexico (lat. $21^{\circ} 0.1^{\prime} \mathrm{N}$; long. $\left.89^{\circ} 34^{\prime} \mathrm{W}\right)$. When plants reached 12 to $15 \mathrm{~cm}$ height and had five leaf pairs $(\approx 3$ weeks old $)$, they were transplanted to plastic bags containing $6 \mathrm{~kg}$ of a red soil (red soils generally form from iron-rich sedimentary rock; they are usually poor growing soils, low in nutrients and humus, and difficult to cultivate, also named luvisol): peatmoss mixture $(2: 1)$, and the bags placed in a greenhouse.

\section{Experimental nutrient treatments}

Treatment application was begun 1 week after transplantation. One liter of an $\mathrm{N}$ or K treatment solution ( $\mathrm{pH} 6.5$ in all cases) was applied per plant once a week. Each treatment consisted of repetitions of five plants and the tested nutrient levels were: $0,1,7.5$, 15,22 , and $30 \mathrm{~mm}$ urea for $\mathrm{N}$ and $0,1,3,6,9$, and $12 \mathrm{~mm} \mathrm{~K} 2 \mathrm{SO} 4$ for K. Plants were watered (water composition: $\mathrm{K}, 1.06 \mathrm{mg} \cdot \mathrm{kg}^{-1}$; $\mathrm{Ca}, 54$ $\mathrm{mg} \cdot \mathrm{kg}^{-1} ; \mathrm{Mg}, 0.29 \mathrm{mg} \cdot \mathrm{kg}^{-1} ; \mathrm{N}$, only traces) on the days the treatments were not applied. Initial nutrient concentration in the soil mix used in control and treatment plants was quantified $\left(\mathrm{K}, 4.26 \mathrm{mg} \cdot \mathrm{kg}^{-1}\right.$; Ca, $280 \mathrm{mg} \cdot \mathrm{kg}^{-1}$; $\mathrm{Mg}, 140 \mathrm{mg} \cdot \mathrm{kg}^{-1}$; $\mathrm{N}$, only traces). As habanero pepper is cultured in both cultivable and noncultivable soils, the majority of people who culture this species do not have conditions to apply any fertilization; therefore, there is not an adequately fertilized protocol 
for this species by this way; plants without treatment were taken as controls.

\section{Flower, pod, and biomass}

After $50 \%$ of the plants began flowering, individual flowers were tagged after pollination using a different number tag each week so that all fruit could be harvested the same number of days after pollination. Week 1 was designated as that in which flowering was first observed and marking continued for 9 weeks after flowering began. Fruit in the same physiological state (at least $30 \mathrm{~d}$ after anthesis) were harvested once a week, weighed, frozen $\left(-80{ }^{\circ} \mathrm{C}\right)$, and freeze-dried until processing.

Sampling was ended $150 \mathrm{~d}$ after transplantation. The aerial portion of all plants was cut at soil surface and separated into leaves and petioles and the roots harvested. Fresh and dry weights were determined for all portions. Leaves, roots, and petioles were ground with a Wiley mill (Thomas Scientific, Swedesboro, NJ) until passing through a $1.3 \times 1.3-\mathrm{mm}$ mesh screen. The micro-Kjeldahl method (Bremner, 1965) was used to determine $\mathrm{N}$ and atomic absorption spectrophotometer to determine K (Martinez-Estévez et al., 2006).

\section{Determination of fruit pungency}

Capsaicinoid extraction. For the capsaicinoid extraction, the fruit of habanero pepper were freeze-dried, ground to a fine powder, and stored in sealed plastic bags in a glass desiccator at room temperature until use. Capsaicinoid extractions were done by incubating $0.1 \mathrm{~g}$ powder in $25 \mathrm{~mL}$ acetone in darkness with orbital shaking $(50 \mathrm{rpm})$ for $6 \mathrm{~h}$ at room temperature. The supernatant was collected and dried in a vacuum in a balloon glass. The pellet was then dissolved in $1.5 \mathrm{~mL}$ acetone (added in $500-\mu \mathrm{L}$ portions); the dissolvent was recovered in $2-\mathrm{mL}$ tubes and centrifuged at $13,000 \mathrm{rpm}$ for $10 \mathrm{~min}$ to eliminate any debris. The supernatant was then placed in 1.5-mL tubes, allowed to dry at room temperature, and the dry pellet stored at freezing until use.

Thin-layer chromatography development. The chromatographic sheets were cut into $5 \mathrm{~cm} \times 5-\mathrm{cm}$ sections and washed in $10 \mathrm{~mL}$ of a chloroform:methanol ( $9: 1$, by volume) mixture for $30 \mathrm{~min}$. The dry pellet was then dissolved in $50 \mu \mathrm{L}$ absolute ethanol (highperformance liquid chromatography grade). Then $20 \mu \mathrm{L}$ of the sample was added to $60 \mu \mathrm{L}$ ethanol $(1: 4)$ and $0.5 \mu \mathrm{L}$ of diluted sample was manually applied $1 \mathrm{~cm}$ above the lower edge of a sheet using a micropipette (Digital Finnpippette 0.5 to $10 \mu \mathrm{L}$; Helsinki, Finland) with ultramicro tips (Daigger TX20573, Helsinki, Finland). Sample volume was delivered in a single, uniform hit and a 5-mm gap left between adjacent samples. Application site diameter was less than $2 \mathrm{~mm}$ in all cases. After loading, application sites were dried with hot air from a hair dryer for $30 \mathrm{~s}$. Separation was performed using a solvent mixture (chloroform : cyclohexane : acetic acid, $70: 20: 10$ ) (Todd et al., 1977) and plates in the solvent mixture were developed three times to produce optimum resolution. The solvent mixture was prepared just before use and added to the chromatography tank 15 min before development to ensure that chamber atmosphere was fully saturated.

Capsaicin quantification. After separation, the plates were air-dried and capsaicin quantified by densitometry using the absorbance reflection mode. Densitometry measurements were done on a Shimadzu CS-930 dual wavelength densitometer with a DR-2 data recorder (Tokyo, Japan). Sample capsaicin concentration was determined based on peak area. A capsaicin standard was used for calibration of the 0.5 to $5.0 \mu \mathrm{g} \cdot \mu \mathrm{L}^{-1}$ capsaicin curve and the corresponding area determined.

\section{Statistical analyses}

Data were analyzed with one-way analysis of variance (Sigma Stat ver. 3.1, SPSS, Chicago). Treatment means were compared with Duncan's multiple range test $(P \leq 0.05)$. Each point is the mean of three independent experiments with five replicates each one \pm SE.

\section{Results and Discussion}

Effects of $K$ and $N$ fertilization on fruiting and flowering in habanero pepper. Flower formation was greater in the $\mathrm{N}$ treatments than in the K treatments (Fig. 1). The effect of $\mathrm{N}$ on flowering was dose-dependent with the highest number of flowers formed in plants treated with $15 \mathrm{~mm} \mathrm{~N}$, more than twice that in the control plants. Although the $1 \mathrm{~mm} \mathrm{~N}$ treatment produced the lowest response (no difference compared with controls), it produced a greater effect than any of the $\mathrm{K}$ treatments (Table 1).

The $\mathrm{K}$ treatments had a negative effect on flowering in habanero pepper (Fig. 1). No dose-dependent effect on flowering was observed for the 1 to $9 \mathrm{~mm}$ treatments. The 12 $\mathrm{mm} \mathrm{K}$ treatment, however, caused a $75 \%$ decrease in flowering versus the control. The other $\mathrm{K}$ treatments caused between $10 \%$ and $30 \%$ less flowering with the $1 \mathrm{~mm}$ $\mathrm{K}$ treatment producing the lowest value (Table 1).

Plants in the $\mathrm{N}$ treatments flowered 2 weeks before those in the $\mathrm{K}$ treatments (Fig. 1). This effect was most significant in the 7.5 $\mathrm{mm} \mathrm{N}$ and $15 \mathrm{~mm} \mathrm{~N}$ treatments, although flower formation was observed in all the $\mathrm{N}$ treatments at this time. All replicates of the $\mathrm{N}$ treatments began flowering $49 \mathrm{~d}$ after transplantation. Very few plants in the $\mathrm{K}$ treatments or controls began flowering at this time, the most notable being a single plant in the $3 \mathrm{~mm} \mathrm{~K}$ treatment that produced eight flowers.

Under the studied greenhouse conditions, the plants in the control treatment experienced very high flower loss resulting in more than $85 \%$ of formed flowers not forming fruit. The $15 \mathrm{~mm} \mathrm{~N}$ treatment reduced this loss to $60 \%$, whereas even the highest dosage of $\mathrm{K}$ treatment only slightly lowered the loss rate; flower loss in the $\mathrm{K}$ treatments never dropped below $70 \%$. Flower detachment was the main cause of flower loss with the earliest flowers (weeks 1 and 2) being more susceptible (data not shown). The lowest loss percentage was observed in flowers marked in week 3 for the $\mathrm{N}$ treatments and in weeks 4 and 5 for the $\mathrm{K}$ treatments.

Fruit formation increased as $\mathrm{N}$ concentration increased with production highest in the $15 \mathrm{~mm} \mathrm{~N}$ treatment (Table 1). Most of these fruit were from flowers marked in week 3 (data not shown). Dosages as high as $30 \mathrm{~mm}$ $\mathrm{N}$ more than tripled fruit production (Table 1). These high fruit set results for the $\mathrm{N}$ treatments can be partially explained by initial stimulation of the flowering process, which leads to greater fruit formation. However, the effect on fruit production was always significantly greater than that on flower formation; for example, flower formation in the $15 \mathrm{~mm} \mathrm{~N}$ treatment was approximately twice that in the control, but fruit formation was more than five times greater. This suggests that $\mathrm{N}$ fertilization has an important effect on the number of flowers and obviously on the fruit formation in habanero pepper.

The $\mathrm{K}$ treatments had no significant effect on fruit production versus the controls (Table 1 ), possibly because they did not favor flowering.

In summary, fertilization with $15 \mathrm{~mm} \mathrm{~N}$ (as urea) is the optimum level for stimulating flowering and fruit formation in habanero pepper, whereas use of $\mathrm{K}$ as the sole fertilizer has no positive effects and may negatively affect flowering.

Effects of $K$ and $N$ fertilization on capsaicin content in habanero pepper fruit. Improving pungency in habanero pepper is vital to improve its overall quality because this characteristic is prized by consumers. All harvested fruit was analyzed, but only fruit harvested in weeks 3 and 4 are shown in Figure 2 because the largest numbers of fruits were formed in this period and it thus exhibits the most representative tendency.

In fruit from flowers that formed in week 3 , capsaicin content decreased by $\approx 70 \%$ in the $1 \mathrm{~mm} \mathrm{~N}$ treatment versus the control treatment (Fig. 2). Capsaicin content then successively increased in the 7.5 and $15 \mathrm{~mm}$ $\mathrm{N}$ treatments followed by decreases at higher $\mathrm{N}$ levels. Although $\mathrm{N}$ fertilization did increase capsaicin content, the highest values produced by the $\mathrm{N}$ treatments did not significantly surpass those in the control treatment.

Capsaicin content also decreased by more than $70 \%$ in fruit from week 4 in the $1 \mathrm{~mm} \mathrm{~N}$ treatment. Thereafter, capsaicin content increased in higher $\mathrm{N}$ content treatments (Fig. 2). Again, none of the $\mathrm{N}$ treatments had capsaicin content higher than the control treatment.

The behavior of capsaicin content in response to $\mathrm{K}$ fertilization was similar in fruit from weeks 3 and 4, although values were slightly lower for fruit from week 3 in some treatments. As occurred in the $\mathrm{N}$ treatments, capsaicin levels in week 3 fruit decreased at lower dosages (as much as $70 \%$ at $3 \mathrm{~mm} \mathrm{~K}$ ) and then increased slowly at higher dosages (at least until the $9 \mathrm{~mm} \mathrm{~K}$ treatment) (Fig. 2). 
NITROGEN

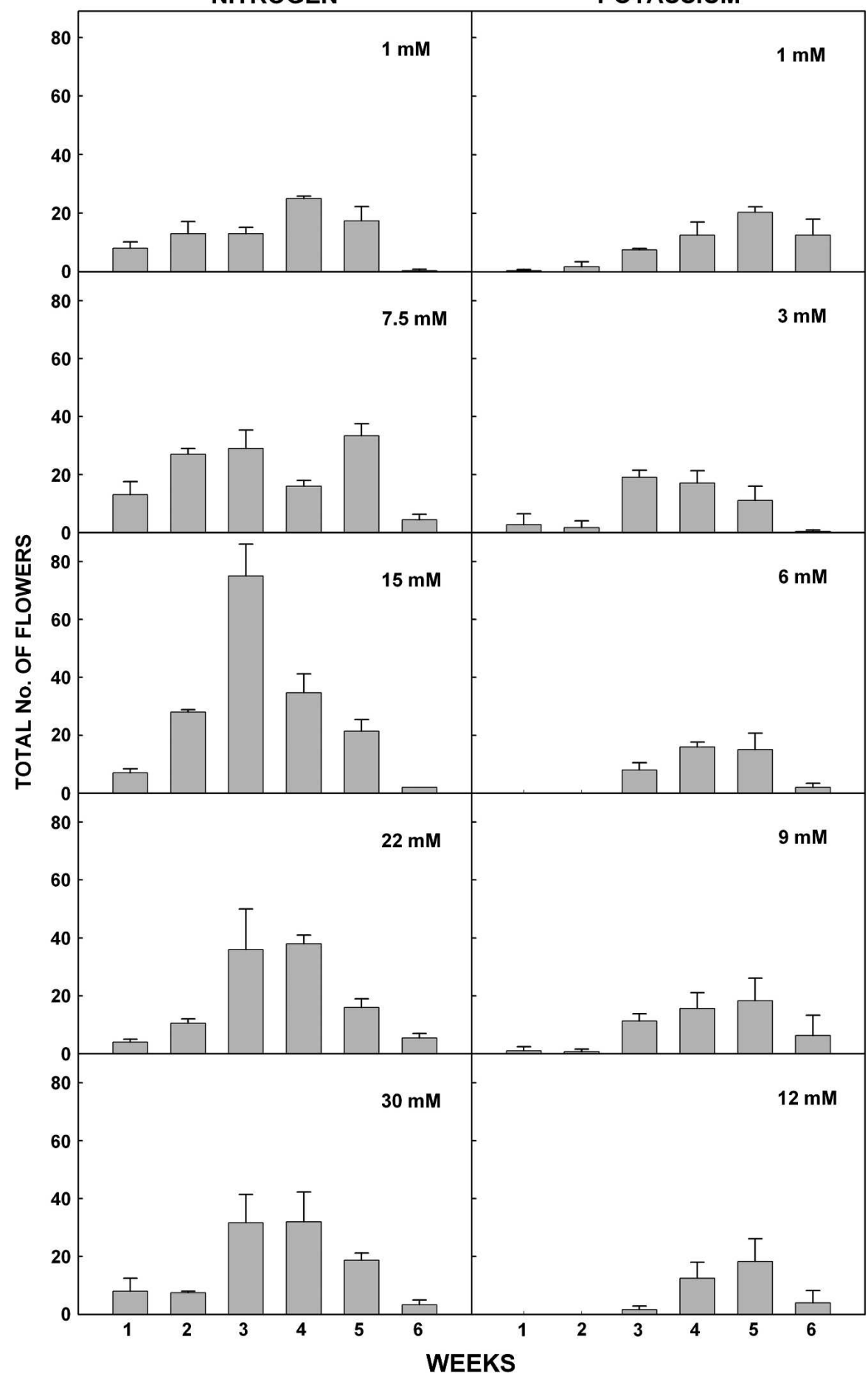

Fig. 1. Effect of nitrogen $(\mathrm{N})$ and potassium $(\mathrm{K})$ fertilization on flower production in habanero pepper Capsicum chinense Jacq plants. Data represent the average number of total flowers per plant (five plants per treatment) per week. Bars show SE of average value $(P \leq 0.05)$. Each point is the mean of three independent experiments with five replicates each one $\pm \mathrm{SE}$.

None of the $\mathrm{K}$ treatments raised capsaicin content above values in the control treatment. This agrees with Johnson and Decoteau (1996), who observed no effect of K on pungency in C. annuum fruit, suggesting that $\mathrm{K}$ apparently does not notably interfere in capsaicin metabolization.

The results of Johnson and Decoteau (1996) for the effect of $\mathrm{N}$ on capsaicin contents in jalapeño pepper fruit (the highest were at $15 \mathrm{~mm} \mathrm{~N}$ ) are very similar to those reported here with the difference of that in our work, there are no differences between treatments. They did not, however, report capsaicin values for a control treatment (without $\mathrm{N}$ fertilization), preventing any determination if the higher values with $\mathrm{N}$ fertilization were equal to or greater than those in plants under fertilization stress.

Capsaicin content is also reported to increase in the fruit of $C$. annum var. Padrón when fertilized with a $13 \mathrm{~N}-40 \mathrm{P}-13 \mathrm{~K}$ for- mula during the vegetative growth period (Estrada et al., 1998). This increase in capsaicinoid accumulation was clearly correlated to decreases in lignin and soluble phenol contents. However, fertilization in this study was done simultaneously with $\mathrm{N}$, $\mathrm{P}$, and $\mathrm{K}$, making it difficult to compare with the present results in which fertilization was done with either $\mathrm{N}$ or $\mathrm{K}$.

The present results agree with the suggestion that pungency increases under stress conditions, including poor soils, but in habanero pepper, the capsaicin content is so high that is very hard to determinate if the fertilization has any effect. Jurenitsch et al. (1979) observed considerable differences in total capsaicinoid content in cultivars grown under greenhouse, laboratory, field study, and regular plantation conditions, highlighting the effect environmental conditions have on capsaicinoid content. In another example, habanero peppers grown under controlled conditions with adequate irrigation and fertilization (e.g., greenhouse conditions) produced less capsaicin, and therefore less pungency, than in plants grown under more stressful conditions (Dzib-Echeverria and Uribe Valle, 2005).

Although lack of fertilization did favor capsaicin accumulation in habanero pepper, capsaicin content also increased as the fertilization rate increased from 1 to $15 \mathrm{~mm} \mathrm{~N}$.

Alkaloid accumulation has also been reported in other crops under $\mathrm{N}$ fertilization regimes. Gerson and Kelsey (1999) observed a 12-fold increase in piperidine-type alkaloids in Pinus ponderosa leaves after fertilization with ammonium nitrate. In the same way, accumulation of ergopeptide-type alkaloids was stimulated in Festuca arundinacea by $\mathrm{N}$ fertilization (Arechavaleta et al., 1992). In this study, the form of $\mathrm{N}$ was important because all the tested nitrate concentrations increased capsaicin content, whereas ammonium was only effective at high concentrations. Festuca arundinacea grows in natural symbiosis with the fungus Acremonium coenophialum, which is responsible for synthesizing this type of alkaloid (Arechavaleta et al., 1992).

Secondary metabolite synthesis increases in the absence of K. In Lupinus angustifolius L., Gremigni et al. (2003) observed an association between $\mathrm{K}$ deficiency and up to an eightfold increase in alkaloid concentrations, whereas the lowest concentrations were produced in the presence of abundant K. Similarly, Mazzafera (1999) reported higher caffeine content in Coffea arabica $\mathrm{L}$. leaves when $\mathrm{K}$ was eliminated from the cultivation medium.

The present results suggest that regulation of capsaicin, a metabolite produced only in the genus Capsicum, occurs in a highly complex interaction with the environment. Within the genus, habanero pepper $C$. chinense produces the highest capsaicinoid levels. Taking these two aspects into account, and considering that the highest capsaicin levels here were recorded under fertilization stress conditions, it can be suggested that the 
levels observed here may reflect the highest threshold for capsaicin synthesis or accumulation. It would be difficult to further increase capsaicin levels using only changes in the $\mathrm{N}$ fertilization regime. Levels of this compound in the studied habanero pepper fruit dropped by as much three times with even minimal $\mathrm{N}$ fertilization (1 mM) (Fig. 2) and then increased significantly as $\mathrm{N}$ dosage increased. This clearly indicates that capsaicin content can be influenced by the $\mathrm{N}$ fertilization regime in a cultivation system. If this regime is managed in conjunction with biochemical, physiological, and nutritional factors, among others, it may be possible to increase capsaicin content beyond this threshold.

Tissue mineral composition ( $N$ and $K$ ). The highest concentration of $\mathrm{N}$ at harvest in those habanero pepper plants fertilized with $\mathrm{N}$ was observed in the leaves, accounting for $44 \%$ to $48 \%$ of total N (Fig. 3). No variation in leaf $\mathrm{N}$ content was observed between treatments, indicating that $\mathrm{N}$ is mostly found and used in the leaves but does not accumulate in this organ. It may also be that leaf $\mathrm{N}$ concentration in these plants was near optimum.

Nitrogen content was similar in the roots (26\% of total) and fruit (29\% of total) of the plants in the $\mathrm{N}$ treatments (Fig. 3). As $\mathrm{N}$ fertilization levels increased, so did root $\mathrm{N}$ accumulation, reaching maximum values between the 7.5 and $15 \mathrm{~mm}$ levels. This represented more than a $60 \%$ increase compared with the roots of plants in the control treatment. After peaking in the $15 \mathrm{~mm}$ treatment, root $\mathrm{N}$ levels remained unchanged even as $\mathrm{N}$ fertilization level increased to $30 \mathrm{~mm}$ (Fig. 3A). These results suggest that $\mathrm{N}$ can be absorbed and accumulated in the roots at $\mathrm{N}$ dosages as high as $15 \mathrm{~mm}$. Fruit $\mathrm{N}$ content increased slowly as $\mathrm{N}$ dosage increased, reaching maximum values at the highest fertilization rate. This behavior in fruit $\mathrm{N}$ content suggests that, as mentioned previously, other factors are regulating capsaicin synthesis in addition to $\mathrm{N}$ concentration (Fig. $3 \mathrm{~A})$.

$\mathrm{K}$ content tended to increase in roots and leaves as $\mathrm{K}$ levels increased but remained unchanged in fruit (Fig. 3B). In the studied plants, $\mathrm{K}$ content was higher and accumulated more in the petioles than in the leaves (data not shown). Leaves contained from $44 \%$ to $53 \%$ of total $\mathrm{K}$, the fruit from $29 \%$ to $34 \%$, and the roots from $15 \%$ to $25 \%$. This indicates that $\mathrm{K}$ did not accumulate in the fruit as $\mathrm{K}$ levels increased but did accumulate in the leaves and roots. The higher $\mathrm{K}$ levels in the petiole versus the leaves suggests that this species does not need such high $\mathrm{K}$ concentrations in its leaves or needs to eliminate $\mathrm{K}$.

Applications of $\mathrm{N}$ had an inverse effect on the uptake of $\mathrm{K}$ and also the application of $\mathrm{K}$ had an inverse effect on uptake of $\mathrm{N}$ in the studied habanero pepper plants, consequently changing plant nutritional condition (Fig. 4). The leaves and roots were most affected in the plant. Potassium content decreased $45 \%$ in leaves and $30 \%$ in roots in the $\mathrm{N}$ treatments (Fig. 4A). The greatest reductions were

Table 1. Effect of nitrogen $(\mathrm{N})$ and potassium $(\mathrm{K})$ fertilization on flowering and fruiting in habanero pepper Capsicum chinense Jacq ${ }^{2}$

\begin{tabular}{cccccc}
\hline & Treatment (mM) & \multicolumn{2}{c}{ Total no. of flowers } & \multicolumn{2}{c}{ Total fruit formed } \\
\hline $\mathrm{N}$ & 1 & 76.67 & \pm 7.13 & 13.00 & \pm 0.82 \\
& 7.5 & 102.00 & \pm 16.00 & 36.67 & \pm 2.63 \\
& 15 & 173.00 & \pm 2.00 & 59.33 & \pm 3.00 \\
& 22 & 106.53 & \pm 3.50 & 36.00 & \pm 8.48 \\
\hline $\mathrm{K}$ & 30 & 56.50 & \pm 8.50 & 38.00 & \pm 4.97 \\
\hline & 1 & 39.00 & \pm 7.00 & 16.33 & \pm 0.50 \\
& 6 & 41.00 & \pm 10.6 & 7.67 & \pm 1.70 \\
& 9 & 40.00 & \pm 2.01 & 7.67 & \pm 1.88 \\
& 12 & 18.00 & \pm 1.00 & 16.67 & \pm 8.00 \\
Control & 0 & 74.00 & \pm 8.73 & 10.33 & \pm 1.50 \\
\hline
\end{tabular}

${ }^{\mathrm{z}}$ Values represent the average number of total flowers (the sum of those in all the evaluated weeks) and total fruit per treatment (five plants) \pm SE.

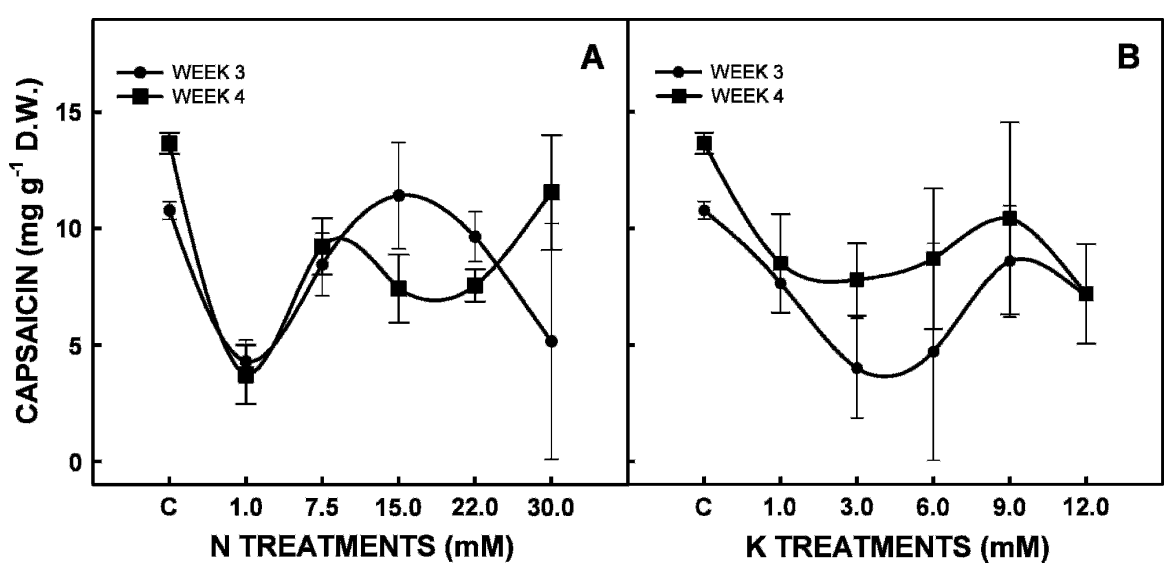

Fig. 2. Effect of nitrogen (A) and potassium (B) fertilization on capsaicin content in habanero pepper Capsicum chinense Jacq. fruit. All analyzed fruit were harvested $30 \mathrm{~d}$ after anthesis. Each value represents the average of five replicates. Bars show SE of average value $(P \leq 0.05)$. Each point is the mean of three independent experiments with five replicates each one \pm SE. $\mathrm{C}=$ control.
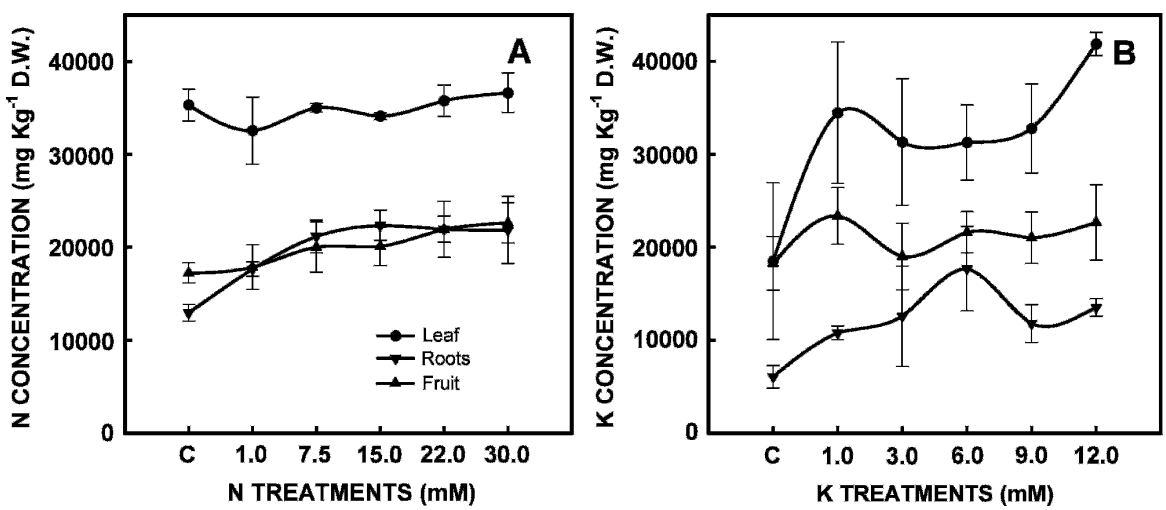

Fig. 3. Endogenous nitrogen (A) and potassium (B) contents in the leaves, fruit, and roots of habanero pepper plants fertilized with $\mathrm{N}$ or $\mathrm{K}$. All plants were harvested $150 \mathrm{~d}$ after transplantation. Each value represents the average of five replicates. Bars show SE of average value $(P \leq 0.05)$. Each point is the mean of three independent experiments with five replicates each one $\pm \mathrm{SE} . \mathrm{C}=$ control.

observed in the $15 \mathrm{~mm} \mathrm{~N}$ treatment, although plants in this treatment did not exhibit visible symptoms of mineral nutrient deficiency. This is similar to the reduced $\mathrm{K}$ concentrations in tobacco plants fertilized with $\mathrm{N}$ in the $\mathrm{NH}_{4}$ form reported by Walch-Liu et al. (2000), who observed a $50 \%$ decrease in old leaves and a $15 \%$ decrease in new leaves.

Fertilization with $\mathrm{K}$ notably affected habanero pepper leaf and root $\mathrm{N}$ concentra- tions. In the $\mathrm{K}$ treatments, leaf $\mathrm{N}$ levels decreased significantly (37\%) beginning at $1 \mathrm{~mm} \mathrm{~K}$ and were lower in all the $\mathrm{K}$ treatments in comparison with the control (Fig. 4B). Root $\mathrm{N}$ content, in contrast, was positively affected by $\mathrm{K}$ fertilization with a maximum increase of $28 \%$ in the $3 \mathrm{~mm} \mathrm{~K}$ treatment. This is probably the result of an increase in $\mathrm{N}$ absorption, which accumulates in the roots, or a retranslocation of $\mathrm{N}$ 

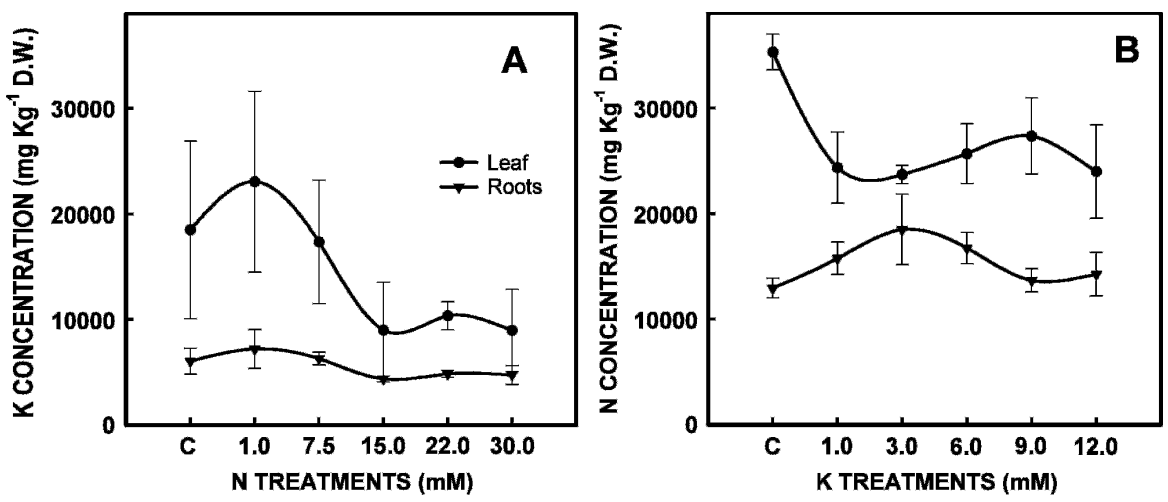

Fig. 4. Effect of nitrogen $(N)$ and potassium $(K)$ fertilization on endogenous $(\mathbf{A}) \mathrm{K}$ and $(\mathbf{B}) \mathrm{N}$ contents in the leaves and roots of habanero pepper plants. Each value represents the average of five replicates. Bars show SE of average value $(P \leq 0.05)$. Each point is the mean of three independent experiments with five replicates each one $\pm \mathrm{SE}$. $\mathrm{C}=$ control.

from the leaves to the roots in response to $\mathrm{K}$ fertilization.

Plant nutritional status influences both the distribution of freshly absorbed nutrients and the redistribution of those previously absorbed. These in turn play a vital role in the relationship between nutrient content and growth. The plants in the $\mathrm{K}$ treatments were shorter and had smaller leaves than those in the $\mathrm{N}$ treatments. For example, average height of the plants in the $6 \mathrm{~mm} \mathrm{~K}$ treatment was $80.0 \pm 4.1 \mathrm{~cm}$, whereas that of plants in the $15 \mathrm{~mm} \mathrm{~N}$ treatment was $103.7 \pm 5.3 \mathrm{~cm}$. The average height of the control plants was $94.6 \pm 1.2 \mathrm{~cm}$. This negative effect of $\mathrm{K}$ on the aerial portion may have resulted from the reduced $\mathrm{N}$ concentrations in these treatments because $\mathrm{N}$ and soluble sugar levels are known to be the main substrates for leaf growth and expansion.

The $\mathrm{K}: \mathrm{N}$ ratio in the leaves and roots was highly variable among the control, the $\mathrm{N}$ treatments, and the $\mathrm{K}$ treatments. In the $\mathrm{N}$ treatments, the average $\mathrm{K}: \mathrm{N}$ ratio was less than 0.5 with an interval between 0.22 and 0.39 (the exception was the $1 \mathrm{~mm} \mathrm{~N}$ with a 0 : 56 ratio). In the $\mathrm{K}$ treatments, by contrast, the average ratio ranged from $1: 0$ to $1: 34$. For example, in the control, the leaf $\mathrm{K}: \mathrm{N}$ ratio was $0: 53$ and that for roots was $0: 46$, for an overall average of $0: 49$. Plants in the $15 \mathrm{~mm}$ $\mathrm{N}$ treatment had a ratio of $0: 26$ in leaves and $0: 19$ in roots for an average of $0: 22$. Finally, those in the $6 \mathrm{~mm} \mathrm{~K}$ treatment had a ratio in leaves of $1: 22$ and one in roots of $1: 05$ for an average of $1: 13$ for the overall plant. The lower $\mathrm{N}$ : $\mathrm{K}$ ratio values observed in the $\mathrm{N}$ treatments may indicate that the plants had a $\mathrm{N}$ supply adequate for growth processes. The higher values in the $\mathrm{K}$ treatments, however, means that growth $\mathrm{N}$ tends to decrease in relation to $\mathrm{K}$, leading to the reduction in growth processes (height, vegetative growth, and fruit production) observed here.

Fruit color was also affected by the different fertilization treatments. The plants in the $\mathrm{N}$ treatment produced fruit with an intense orange color, whereas those in the $\mathrm{K}$ treatments produced pale orange fruit (data not shown). This characteristic could add commercial value to habanero pepper fruit because a brighter color may make it more attractive to consumers. This is apparently the first report in habanero pepper of fertilization treatment affecting the metabolism of pigments (carotenoids) responsible for fruit color. Previous studies have focused on carotenoids composition and changes during fruit ripening in $C$. annuum (Deli et al., 1996; Hornero-Méndez and MinguezMosquera, 2000) but without addressing the effect of cultivation conditions on these aspects.

Like other plants that produce secondary metabolites, habanero pepper plants produce a higher proportion of these metabolites when under stress, nutrient stress in this case. Although capsaicin levels decreased at low $\mathrm{N}$ levels, they increased as $\mathrm{N}$ levels were raised, eventually attaining the same relative proportion at $15 \mathrm{~mm} \mathrm{~N}$ as in the fertilizer-stressed plants. This $\mathrm{N}$ fertilization level (in the form of urea) is therefore recommended as the optimum concentration for habanero pepper production because it 1) increases flower formation; 2) increases fruit formation; 3) leads to less flower loss; 4) does not affect fruit capsaicin content; and 5) increases plant height. In addition, producers in the region tend to use urea as the sole fertilizer, which can exacerbate this problem.

Potassium does not appear to play a role in capsaicinoid metabolism in habanero pepper, and application of $\mathrm{K}$ as the sole fertilizer can negatively affect growth and production. This is probably a response to the significant reduction in leaf $\mathrm{N}$ content caused by $\mathrm{K}$ fertilization.

Finally, the leaf $\mathrm{K}: \mathrm{N}$ ratio was found to be more indicative of habanero pepper nutritional and production condition than the concentrations of these elements. A ratio less than $0: 5$ means the plant is in optimum nutritional conditions for adequate growth and production. A ratio greater than $1: 0$ may indicate a scarcity of $\mathrm{N}$ in relation to $\mathrm{K}$, which can limit leaf growth and productivity. Both elements are obviously important to proper development and production in habanero pepper, and future research needs to focus on determining optimum levels when simultaneously applying both nutrients.

\section{Literature Cited}

Arechavaleta, M., C.W. Bacon, R.D. Plattner, C.S. Hoveland, and D.E. Radcliffe. 1992. Accumulation of ergopeptide alkaoids in symbiotic tall fescue grown under deficits of soil water and nitrogen fertilizer. Appl. Environ. Microbiol. 58:857-861

Bernal, M.A., A.A. Calderon, R.D. Muñoz, A. Ros Barceló, and F. Merino de Caceres. 1993 Capsaicin oxidation by peroxidase from Capsicum annumm L (var. annumm) fruits. J. Agr. Food Chem. 41:1041-1044.

Bosland, P.W. 1992. Chiles: A diverse crop. HortTechnology 2:6-10.

Bremner, J.M. 1965. Total nitrogen. In: Black, C.A. (ed.). Methods of soil analysis, part 2 Amer. Soc. Afron., Madison, WI, 1238-1286.

Bryant, J.P., T.P. Clausen, P.B. Reichardt, M.C McCarthy, and R.A. Werner. 1987. Effect of nitrogen fertilization upon the secondary chemistry and nutritional value of quaking aspen (Populus tremuloides Michx.) leaves for the large aspen tortrix [Choristoneura conflictana (Walker)]. Oecologia 73:513-517.

Contreras Padilla, M. and E.M. Yahia. 1998 Changes in capsaicinoids during development, maturation, and senescence of chile peppers and relation with peroxidase activity. J. Agr. Food Chem. 46:2075-2079.

Deli, J., Z. Matus, and G. Tóth. 1996. Carotenoid composition in the fruits of Capsicum annuum cv. Szentesi Kosszarvú during ripening. J. Agr. Food Chem. 44:711-716.

Dzib-Echeverria, R. and G. Uribe Valle. 2005. La fertilidad de los suelos luvisoles ródicos y el uso de fuentes de fertilizantes en chile habanero. Nutrition and water management. Second World Pepper Convention. 2:205209.

Epstein, E. and A.J. Bloom. 2005. Nutrient absorption by plants. In: Epstein, E. and A.J. Bloom (eds.). Mineral nutrition of plants: Principles and perspectives. 2nd Ed. Sinauer Associates, Inc., Sunderland, MA.

Estrada, B., F. Pomar, J. Diaz, F. Merino, and M.A. Bernal. 1998. Effects of mineral fertilization supplementation on fruit development and pungency in Padron peppers. J. Hort. Sci. Biotechnol. 73:493-497.

Gerson, E.A. and R.G. Kelsey. 1999. Piperidine alkaloids in nitrogen fertilized. J. Chem. Ecol. 25:2027-2039.

Gremigni, P., J. Hamblin, D. Harris, and W.A. Cowling. 2003. The interaction of phosphorus and potassium with seed alkaloid concentrations, yield and mineral content in narrowleafed lupin (Lupinus angustifolius L.). Plant Soil 253:413-427.

Harvell, P.K. and P.W. Bosland. 1997. The environment produces a significant effect on the pungency of chilies. HortScience 32: 1292.

Hornero-Méndez, D. and M.I. Mínguez-Mosquera. 2000. Xanthophyll esterification accompanying carotenoid overaccumulation in chromoplast of Capsicum annuum ripening fruits is a constitutive process and useful for ripeness index. J. Agr. Food Chem. 48:1617-1622.

Jaworski, C.A., S.J. Kays, and D.A. Smittle. 1978. Effects of nitrogen and potassium fertilization in trickle irrigation on yield of pepper and pole bean. HortScience 13:477-478.

Johnson, C.D. and D.R. Decoteau. 1996. Nitrogen and potassium fertility affects jalapeño pepper 
plant growth, pot yield and pungency. HortScience 31:1119-1123.

Jurenitsch, J., W. Kubelka, and K. Jentzsch. 1979. Identification of cultivated taxa of Capsicum-Taxonomy, anatomy, and composition of pungent principles. Planta Med. 35:174 180.

Kainulainen, P., J. Holopainen, V. Palomäki, and T. Holopainen. 1995. Effect of nitrogen fertilization on secondary chemistry and ectomycorrhizal state of Scots pine seedlings and on growth of grey pine aphid. J. Chem. Ecol. 22:617-639.
Martínez-Estévez, M., N. Ruiz-Lau, R.E. MayUluac, A. Guzmán-Antonio, F. Quintal-Tun, and R. Pacheco-Arjona. 2006. Dynamics and distribution of nutrients during the development of plantlets of Habanero pepper (Capsicum chinense Jacq.). HortScience 41:477-479.

Mazzafera, P. 1999. Mineral nutrition and caffeine content in coffee leaves. Bragantia. Campinas 58:387-391.

Raese, J.T. and S.R. Drake. 1997. Nitrogen fertilization and elemental composition affect fruit quality of Fuji apples. J. Plant Nutr. 20:17971809.
Soria Fregoso, M.J., J.A. Trejo Rivero, J.M. Tun Suarez, and R. Teran-Saldivar. 2002. Paquete tecnológico para la producción de chile habanero (Capsicum chinense Jack). Instituto Tecnológico de Mérida 2:3-74.

Todd, P.H., Jr., M.G. Bensinger, and T. Biftu. 1977. Determination of pungency due to capsicum by gas-liquid chromatography. J. Food Sci. 42:660-680.

Walch-Liu, P., G. Neumann, F. Bangerth, and C. Engels. 2000. Rapid effects of nitrogen form on leaf morphogenesis in tobacco. J. Expt. Bot. $51: 227-237$ 